and myself while in Calcutta on the Royal Society's Malaria Commission examined 80 such cases of malarial cachexia, and in none of these did we find parasites, pigmented leucocytes, or an increase of the large mononuclear leucocytes. Post mortem there was pigment in the organs but again no parasites. It can serve no useful purpose to classify such cases with those in which there is an active infection with para ites in the blood. Those who are responsible for fever statistics, civil and military, have at present no option left them. They would as a whole, I think, welcome a change which would give to the figures a more definite meaning than they now bear.

I am, Sirs, yours faithfully,

J. W. W. STEPHENS,

Jan. 17th, 1903. Lecturer, Liverpool School of Tropical Medicine.

\section{WEATHER AND SMALL-POX.}

To the Editors of THE LANCET.

SIRs,-Thinking that the subjoined fact taken from $\mathrm{Mr}$ William Digby's lately published work, "Natural Law in Terrestrial Phenomena" (William Hutchinson and Co.), may interest your readers I venture to send it to you. The above author has given a full and remarkable account of Mr. Hugh Clements's investigations on "weather forecasting" for many years past, and whilst treating of lunar cycles makes the following statement: "The next lunar cycle in order is that of 130 years. This cycle contains the lunar node cycle of 18.6 years just seven times, and is a multiple of the 10 and 13 years' lunar cycles. The weather of 1902 and of 1772 is so similar that there were small-pox epidemics in both years" (p. 321).

Jan. 15th, 1903. I am, Sirs, yours faithfully,

ALFRED HAVILAND.

\section{A DISCLAIMER.}

\section{To the Editors of THE LANCET.}

SrRs, - Some weeks since I received a book of testimonials relating to a product known as "odol," and I was astounded to see that one of them purported to have been given by me. $I$ at once wrote to the proprietors pointing out that $I$ had never given the testimonial in question, nor, in fact, expressed any opinion of my own about their product, and requesting that it should at once be cancelled. I received in reply a courteous letter acknowledging that $I$ had never given a testimonial or authorised the use of my name in connexion therewith and promising to take steps to prevent its further publication.

In a copy of the book which reached me from the office last night the testimonial again appears, the proprietors apparently considering that I ought to be satisfied with a tiny "erratum" in a corner of the last page. In order to clear myself of any complicity in the matter I trust that you will allow me to repudiate all responsibility in connexion with this unauthorised use of my name, an abuse which has drawn upon me the notice of the Censors of the Royal College of Physicians of London. It is within my knowledge that at least one other testimonial therein contained has also been published without authority.

I am, Sirs, yours faithfully

Alfred S. GuBb, M. D. Paris.

Gower-street, W.C., Jan. 17th, 1903.

** The proprietors of "odol" will, we trust, see the extreme impropriety of the conduct imputed to them and will take steps to remedy the mischief and to obviate its recurrence.-ED. L.

\section{THE HUNTERIAN MUSEUM. \\ To the Editors of THE LANCET.}

SiRs,-I would like to invite the attention of the museum committee to the growing practice of holding tutorial classes in the Hunterian Museum, a practice which makes almost impossible the stady and research for which such a museum is intended. Sometimes I notice that the instruction, or rather coaching, has no reference to the specimens, and the museum thus becomes a class-room for the unattached crammer. As the various medical schools are equipped with museums for the purpose of elementary instruction $I$ would ask that the Hunterian Museum be reserved for silent study only. I am, Sirs, yours faithfully, Jan. 17th, 1903.

M.D. LoND., F.R.C.S.
NOTES FROM INDIA.

\section{(From OUR SPECIAL CORRESPONDHNT.)}

\section{The Great Coronation Durbar : some of the Medical and} Sanitary Arranyements. - The Plague Mortality.

IT is no small thing to make medical and sanitary arrangements for a camp containing. 150,000 people and covering an area of nearly 40 square miles. Practically the whole of this vast undertaking is in the hands of a special staff, with Colonel C. J. Bamber, I.M.S., as administrative sanitary officer ; Colonel H. B. Thornhill, I.S C., as executive sanitary officer ; Major F. Wyville Thomson, I.M.S., as chief assistant administrative officer ; and Captain C. H. James, I.M.S., as special plague officer. The numerous camps, including the military, are grouped into six sanitary circles, each with its sanitary inspector and large staff of sweepers. There is a medical officer in charge of each camp; a hospital tent with staff has also been arranged for $\epsilon$ ach camp. For infectious diseases, including plague, there are four segregation hospitals. For ordinary illness provision is made for treating cases in their own tents. by the medical officer in charge, but if serious there is the Civil Hospital in the city. For natives there is a hospital of 50 beds in addition to the camp tent hospitals which also act as outdoor dispensaries. Those are very briefly the medical arrangements. The water-supply is partly from the waterworks of the city and partly from wells. The latter have been utilised because many natives will not use pipe water. The chief supply has been distributed from the water-works in iron pipes. This has amounted to nearly 2,000,000 gallons a day-about double the ordinary supply. Running through the huge camp is a canal from the river Jumna which has been largely availed of for the purposes of watering the roads. The water from the works is pumped up to a reservoir on the " ridge," from which it is distributed throughout the camp at a fairly good pressure, standposts being very numerous. The water supplied for drinking is, I am told, of satisfactory purity. The wells have all been cleaned out and treated with permanganate of potash and each well has a guard of two men to prevent its being contaminated. Bathing, except where special arrangements are made in tents, has to be done in the Jumna or canal and the washing of clothes is only permitted in the river. The excreta are removed from the tents to iron receptacles, one of which is supplied for every 50 persons. The receptacles are carted some distance off and the night-soil is deposited in trenches. This is the general rule but some of the camps have arranged for trenching close at hand. Latrines are provided for servants and public urinals, consisting of a mat-screen surrounding a heap of sawdust or pulverised dry earth, are freely distributed. These latter have been found inoffensive, but the material requires to be stirred up from time to time. Waste water and other refuse from the kitchens are disposed of in absorption pits, consisting of holes dug in the ground and filled with broken bricks, and bath water from tents is thrown on grass plots or flower beds. It is not the individual details which are of interest but the vastness of the collective preparations and up to the present (Jan. 2nd) all the arrangements have worked exceedingly well, but the strain on the staff during the present busy week is tremendous.

I regret to have to record the death from appendicitis of Dr. E. C. Pettifer, one of the special plague medical officers in Calcutta. He formerly practised in Essex, but since 1897 has been doing plague work in India.

The mortality from plague throughout India continues to rise. For the week ending Dec. 20th 14,203 deaths are recorded, compared with 13,415 in the preceding seven days and 9198 in the corresponding week last year. The Bombay Presidency returns 7056 deaths ; United Provinces, 1639; the Punjab, 1734; Mysore State, 871; Hyderabad State, 641 ; Madras Presidency, 478 ; Berar, 316 ; Bombay City, 130 ; Karachi, 16 ; and Calcutta, 22. There is an increase in Madras, Bengal, and United Provinces, but reduced numbers are returned for Bombay and the Punjab. The epidemic, however, is spreading. Plague has been officially declared at Jubbulpore and also for the first time in Lucknow. In several important cities it is developing - viz, in Benares, Allahabad, and Meerut. Inoculation for plague in the Punjab is to be recommenced during the second week in January at those places where the natives show a disposition to take advantage of it. Although there 